COST OF PROCESSING FUEL. FROM A MOLTEN SALT,

FUSION/FISSION, HYBRID REACTOR BLANKET*

\author{
J. S. Watson \\ W. R. Grimes \\ CONF $-850405--11$ \\ Chemical Technology Division \\ Oak Ridge National Laboratory \\ Oak Ridge, Tennessee 37831 \\ and \\ D. E. Brashears \\ Engineering Division \\ Martin Marietta Energy Systems, Inc. i, $15:$ \\ Oak Ridge, Tennessee 37831
}

For presentation at the ANS National Topical Meeting on Tritium

Technology in Fission, Fusion and Isotopic Applications, Dayton, Ohio, April 30-May 2, 1985 and for possible publication

in Fusion Technology.

\title{
DISCLAIMER
}

This report was prepared as an account of work sponsored by an ag:ncy $0_{\text {i }}$ the United States Government. Neither the United States Government nor any agency th ereof, wor any of their employees, makes any warranty, express or implied, or assumes any legil liabiaty or responsibility for the accuracy, completeness, or usefulness of any information, apparatus, product, or process disclosed, or represents that its use would not infinge privately owned rights. Reference herein to any specific commercial product, process, or service by trade name, trademark, manufacturer, or otherwise does not necessarily constitute or imply its endorsement, recommendation, or favoring by the United States Government of any agency thereof. The views and opinions of authors expressed herein do not necessarily state or reflect those of the United States Government or any agency thereof.

\footnotetext{
* Research sponsored by the Office of Fusion Energy, U.S. Department of Energy under contract DE-ACO5-840R21400 with Martin Marietta Energy Systems, Inc.
} 
COST OF PROCESSING FUEL FROM A MOLTEN SAJT,

FUSION/FISSION, HYBRID REACTOR BLANKET

J. S. WATSON and W. R. GRIMES, Chemical Technology Division Oak Ridge National Laboratory

Oak Ridge, Tennessee 37831

(615) $574-6795$

and

D. E. BRASHEARS, Engineering Division

Martin Marietta Energy Systems, Inc.

Oak Ridge, Tenriessee 37831

ABSTRACT

A conceptual flowsheet was prepared for continuous processing of molten salt used as the blanket material for breeding tritium and fissile breeding material $\left(233^{U}\right)$ in a fusion/fission hybrid reactor. The salt was assumed to be 70 mol $\% \mathrm{LiF}, 12 \mathrm{~mol} \% \mathrm{BeF}_{2}$, and 18 mol $\% \mathrm{ThF}_{4}$ which has a melting point of $\sim 530^{\circ} \mathrm{C}$. The hybrid reactor generates $3000 \mathrm{MWe}$, and the blanket contains $65 \mathrm{~m}^{3}$ of the breeding salt.

The molten salt processing system can be viewed as consisting of two major parts, one for removing tritium and one for renoving ${ }^{23}{ }^{3}$. The tritium removal system is relatively simple but requires very high salt-processing rates, $\sim 667 \mathrm{~L}$ salt/min. The principal process steps are: mixing of helium gas with the salt, separating the helium-tritium mixture from the salt, and removing the tritium from the helium. Transmutation of lithium to tritium and helium makes the salt more oxidizing and corrosive, so fresh lithium is added before the salt is returned to the reactor blanket to replace that lost by transmutation. The inert-gas fission products ( $\mathrm{Kr}$ and $\mathrm{Xe}$ ) are removed by cryogenic absorption into 
fluorocarbons. Tritium is removed from the helium stream by cryogenic adsorption on activated charcoal beds.

After tritium removal, a much smaller salt stream is diverted from the salt returning to the reactor blanket for removing and recovering $290 \%$ of the fissile uranium. The processing rate of $7.5 \mathrm{~L} / \mathrm{min}$ is determined by the maximum uranium concentration allowed in the salt $(0.03$ mol \%). The uranium is removed by batch fluorination, and accumulation tanks must be provided both for feeding the fluorinator and for dispensing salt to subsequent process steps. Adequate provisions are also needed for removing heat from the salt in the accumulation tanks.

Although most of the salt is returned to the reactor blanket after uranium removal, a small stream $(\sim 58 \mathrm{~L} / \mathrm{d})$ is civerted to a decay-waste system. This bleed stream provides a means for removing fission products and for retaining the desirable Li/Th/Be ratio in the salt. After 260-d storage, essentially all of the ${ }^{233} \mathrm{~Pa}$ has decayed, and the salt then undergoes a final batch fluorination before being sent to waste storage.

The cost estimates presented here are not based upon detailed designs and must be viewed as preliminary and very approximate. There are also uncertainties in the feasibility of some process steps. However, in this studiy an attempt has been made to use process steps that were previously demonstrated for the Molten Salt Breeder Reactor (MSBR), were undemonstrated but considered feasible, or were viewed ar reasonable extrapolations of current technology. None of the process steps listed appear to be unreasonable or to involve more uncertainties than other aspects of the hybrid reactor concept. These estinates were prepared principally for 
comparing the costs of various blanket systems; so no estimates were prepared for facilities that are common to all blanket concepts (e.g., the building, any containment facilities required within the reactor building, or the standard utility services). The cost estimates also did not inclucie any waste management operations other than removal of the last traces of uranium from the bleed salt.

The total identified capital costs for the hybrid molten salt reactor were estimated to be $\$ 53,108,000$ in 1984 dollars, but the uncertainty factors may cause this to vary as much as $\$ 20$ million. These costs include $\$ 13,822,000$ for materials, which is the principal basis for the total cost estimate. From the materials costs, construction costs were estisated to be $\$ 18,541,000$. An additional $30 \%(\$ 9,709,000)$ was inclujed for engineering, and $50 \%$ of the total $(\$ 21,036,000)$ was added for contingency costs.

THE FYBRID REACTOR CONCEPT

The processes evaluated in this study are intended to service a molten salt blanket concept currently under study at the Lawrence Livermore National Laboratory (LLNL).1,2 The reactor is a tandem-mirror fusion reactor with a molten salt blanket that generates both the tritium necessary to fuel the fusion reactions and the $233 \mathrm{v}$ to fuel other (fission) reactors. The fusion power from the tandem-mirror reactor is 3000 MWe. Additional power is generated by fission in the blanket, but this is a small fraction of the total and will likely be minimized to control accumulation of fission products in the blanket. Other blanket 
options are being considered in the LLNL program, and the results from this study will be compared with those for other blanket concepts.

The proposed molten salt blanket (shown schematically in Fig. 1) consists of modules filled with 1 -cm-diam beryllium spheres surrounding pipes through which the wolten salt breeding material is slow circulated. Helium coolant flows to the "first" wall facing the plaswa, then through the 60-cr-thick, berylilum-filled region, then to a 40-cm-thick reflector area containing graphite slabs, and finally to the reactor power generation system. The molten salt is processed for recovery of the bred tritium and uranium, rather than for heat recovery.

The salt mixture chosen for this blanket contains 18 mol \% ThF 4 , 70 mol \% LiF, and 12 pol\% $\mathrm{BeF}_{2}$; the melting point is $\sim 530^{\circ} \mathrm{C}$, with a density at $600^{\circ} \mathrm{C}$ of $3.87 \mathrm{~g} / \mathrm{cm}^{3}$. The salt volume $\left(\sim 65 \mathrm{~m}^{3}\right)$ constitutes $-9.1 \%$ of the rotal blenhet volume. Addicional salt will be required in the circulation and procesing systems outside the blanket.

A number of minor copponents will be present in the salt mixture. The concentration of bred uranium in the mixture will be maintained at or beiow 0.03 mol \% by the process system. The solubility of tritium gas in the salt will also be extremely low, provided the oxidation/reduction state of the salt is baintained sufficiently reducing that the tritium fluoride concentration can be neglected. Small quantities of zorrosion and fission products will always be present, but they are not expected to affect the physical properties of the salt significantly. The concentrations of all impurities will be controlled by the process system and/or the salt bleed rate. 
$F 16 \mathrm{~K}$
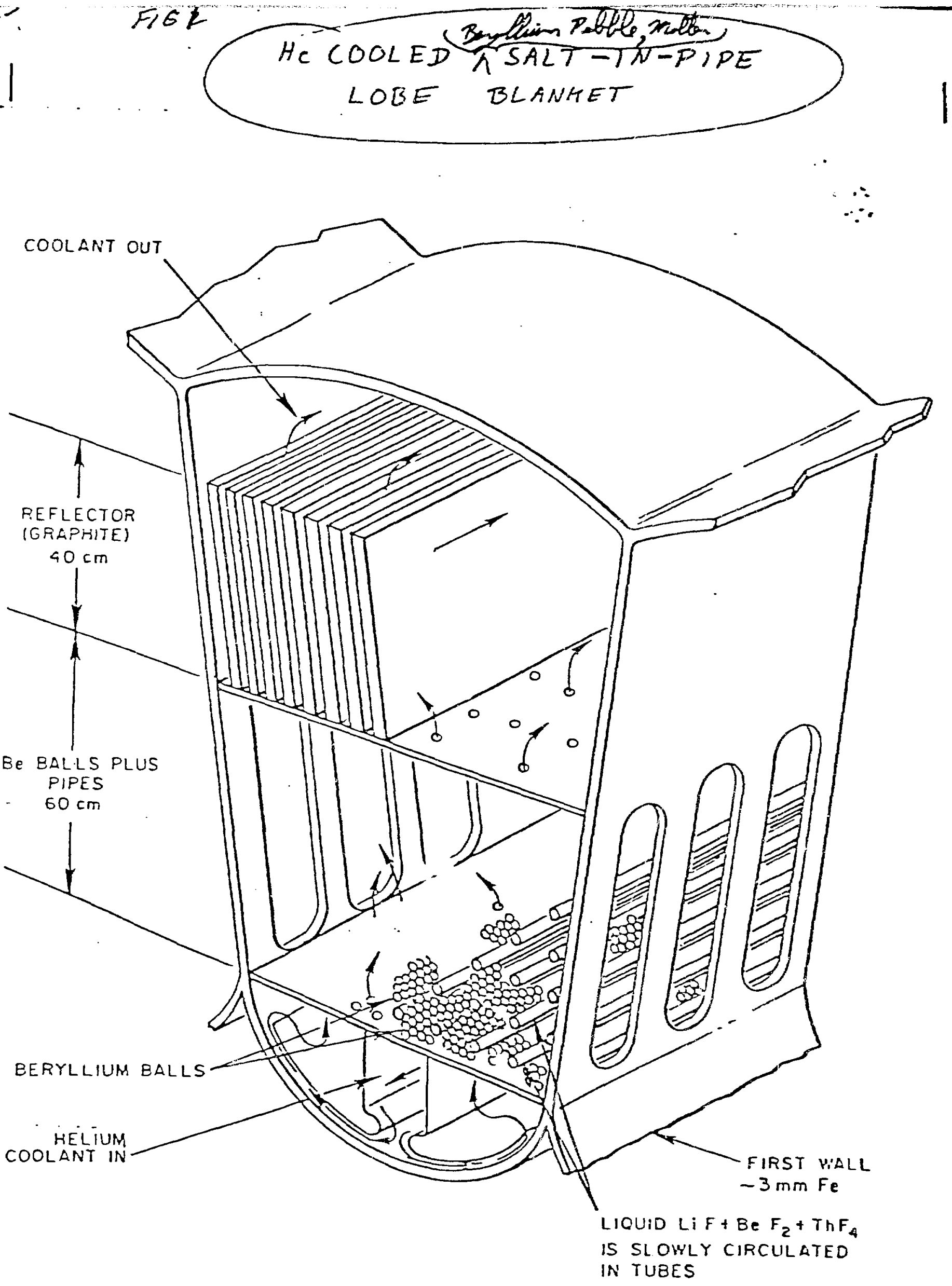

zig. 1 
As mentioned earlier, the oxidation/reduction state of the salt is an important parameter since it controls the salt corrosion rate. The importance and difficulties of controlling the oxidation state of the salt are enhanced by the transmutation of lithium to tritium and helium. In effect, tritium production involves the conversion of lithium fluoride to tritium fluoride, with a resulting increase in the corrosiveness of the salt. The slight uranium content of the salt can be partially reduced from $\mathrm{U}^{4+}$ to $\mathrm{U}^{3+}$, and the ratio of these ions is a useful measure of the corrosion potential of the salt. The uranium concentration also serves an important function in providing some buffering capacity so that a smal1 but significant degree of oxidation can occur before the salt becomes corrosive.

\section{PROCESS REQUIREMENTS}

The process systers must provide four services:

1. Recovery of tritiun at a rate sufficient to prevent the buildup of tritium pressure that will result in unacceptable permeation rates.

2. Recovery of uranium at a rate sufficient to avoid excessive formation of radioactive fission products in the salt.

3. Restoration of the oxidation/reduction state of the salt by addition of a metal such as lithium.

4. Maintenance of the overall salt composition by the proper bleeding of used salt and the addition of fresh salt mixtures. (This includes maintaining the proper ${ }^{6} \mathrm{Li}$ content.) 
The Iate at which tritium permeates the piping is difficult to estimate accurately, since it is affected by important unknown parameters such as the amounts of oxides and other films on the surfaces and the resistance of these films to permeation. Although film resistances are known to form on many surfaces which reduce permeation rates by a few hundred fold, the remaining permeation race in the hybrid reactor would still be high enough that secondary containment would be required.

For this study, the walls of pipes transporting the molten salt were assumed to have sufficient resistance that the permeation rate would not affect the tritium inventory significantly. Doubly contained piping would be required to prevent excessive contamination of the surrounding atmosphere. The solubility of tritium in this salt is now known, but it is believed to be low (perhaps $2.712 \times 10^{-3} \mathrm{~mol} / \mathrm{cm}^{3}-\mathrm{Pa}$ at $650^{\circ} \mathrm{C}$. As long as the tritium is reduced to the elemental state, its low solubility makes tritium removal relatively simple in principle. As noted earlier, the major potential problem is the buildup of tritium pressure within the salt. The proposed tritium removal system will involve the injection of helium gas bubbles into the salt stream. Since tritium concentration in the gas is more than three hundred times that in the salt, the circulation of a relatively small volume of helium gas with the salt can reduce the tritium concentration in the salt (and thus the tritium pressure) considerably. An injection of $560 \mathrm{~L} / \mathrm{min}$ (STP) of helium into the salt is needed to maintain acceptable tritium concentrations with a salt circulation rate of $32.5 \mathrm{~m}^{3} / \mathrm{min}$. Note that this corresponds to a process cycle (residence) time of only 2 min. This circulation rate is not, 
however, as rapid as would be required if salt circulation were used to remove the heat generated in the blanket.

The addition of reductant to the salt to maintain an adequate $\mathrm{U}^{3+}$ concentration also requires a rapid salt circulation rate, though not as rapid as that needed for tritium removal. A salt circulation rate of $\sim 333 \mathrm{~L} / \mathrm{min}$ is adequate for reductant additions. "This corresponds to a process cycle time of $\sim 3.25 \mathrm{~h}$.

The blanket produces $0.5 \mathrm{~g}$ of ${ }^{233} \mathrm{U}$ per second. To maintain the concentration of uranium in the salt at $<0.03 \mathrm{~mol} \%$ will require a salt processing rate of $7.51 \mathrm{~L} / \mathrm{min}$, if $90 \%$ of the uranium is removed in each pass. This corresponds to a 6 -d reactor residence time for the salt between process cycles.

\section{PROCESS DESCRIPTICN}

\section{Tritium Removal}

As noted previously, the tritium removal concept is simple. A small volume of helium is injected into the salt as it enters the blanket, and the tritium is removed as the helium is separated from the salt in the bowl of the centrifugal salt pump. The helium addition to the salt serves to flush the tritius from the pump bowl, but the high salt circulation rates required demand large pumping capacities and relatively complex piping and manifold systems. One potential manifold system is shown in Fig. 2. The entire reactor blanket in this system contains 50 modules. Five pumps with capacities of $6500 \mathrm{~L} / \mathrm{min}$ each are used to circulate the salt. Each pump has 6-in. inlet and outlet pipes which service 10 
ORNL OWG 85-295

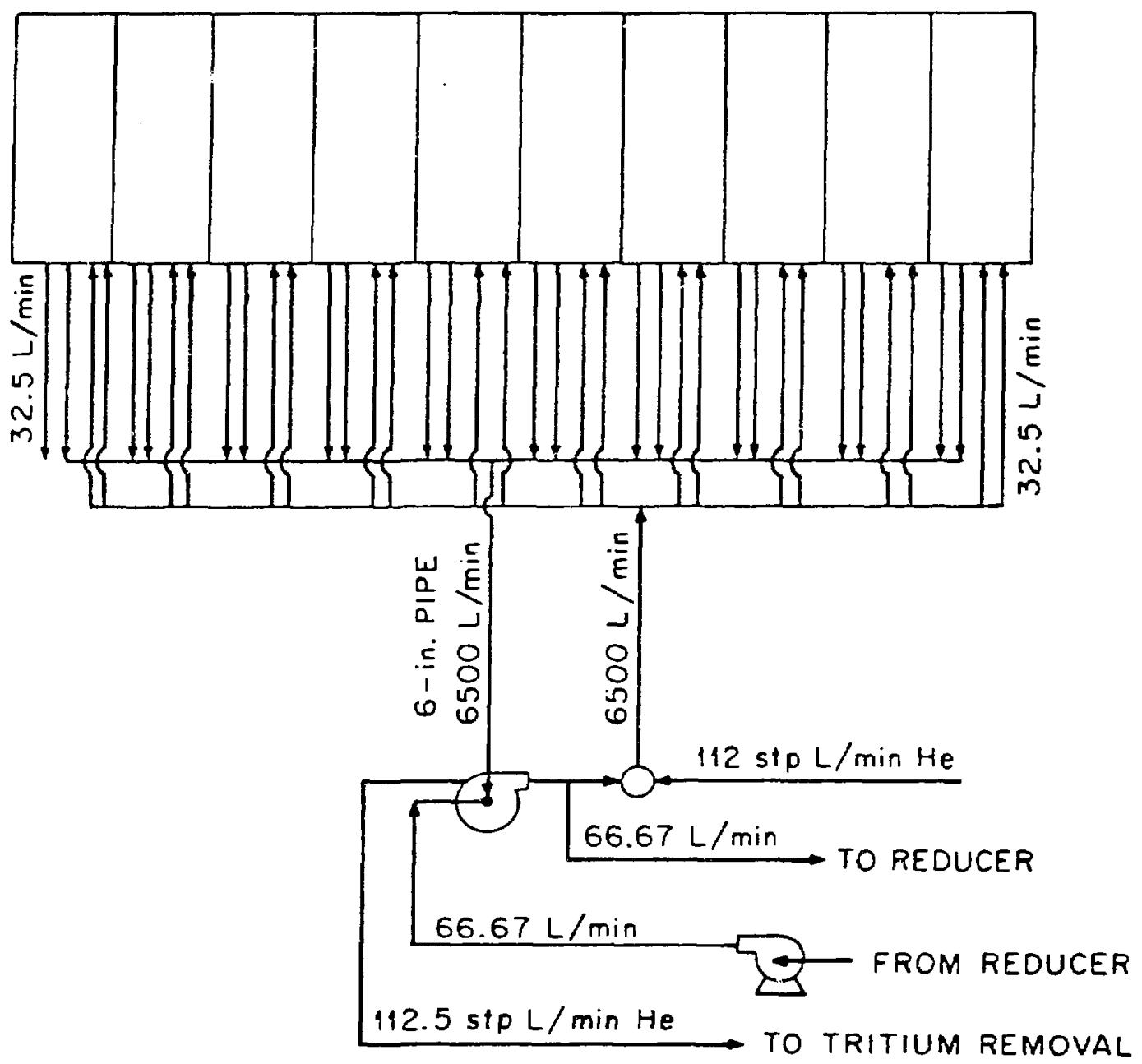

PIPES TO AND FROM EACH MODULE ARE 3 - in. ID

HEADER PIPES TO AND FROM PUMP ARE $5.5-\mathrm{i}$. ID

SALT $17 \mathrm{C} \mathrm{mol} \%$ LiF $\left.-12 \mathrm{~mol}^{\%} \mathrm{BeF}_{2}-18 \mathrm{~mol}^{\%} \mathrm{ThF}_{4}\right)$ WITH EACH MODULE $1.3 \mathrm{~m}^{3}$;

TOTAL VOL WITHIN ALL MODULES $=65 \mathrm{~m}^{3}$; TOTAL SALT INVENTORY IN COMPLETE SYSTEM ASSUMED TO BE $100 \mathrm{~m}^{3}$.

ALL PIPES SHOWN MUST BE DOUBLE WALL WITH ANNULUS FLUSH WITH He. 
blanket modules. Branching parallel 3-in. inlet and outlet pipes are connected to each module (see Fig. 2). The flow rate in each 3 -in. pipe is $3.25 \mathrm{~L} / \mathrm{min}$. Five sets of 10 modules such as those shown in Fig. 2 are required for the entire reactor which contains 50 modules. All of the piping outside the blanket is double contained, and tritiun permeating the inner pipe is recovered from helium flushed through the region between the inner and outer pipes. Note that side streams with flows of 66.7 $\mathrm{L} / \mathrm{min}$ are taken from the pumps for the addition of lithium to maintain the proper reduction potential in the salt.

Tritium is removed from the helium purge gas as shown in Fig. 3. The $112.5 \mathrm{~L} / \mathrm{min}$ (STP) of helium from each of the pump purges is combined with $\sim 325 \mathrm{~L} /$ min of helium flush from secondary enclosures around the external piping and a saller stream of $6.5 \mathrm{~L} /$ min produced in the reduction system. The tritium-bearing helium is first cooled in a regenerative heat exchanger and filtered to remove any particulates or salt particles entrained in the pumps. The gas then goes to a cryogenic absorption unit for removal of air (oxygen and nitrogen) and the gaseous fission products $\mathrm{Kr}$ and $\mathrm{Xe}$. The absorption system is similar to that reported for cleanup of HTGR process off-gases. The detailed cost estimate for the gas absorption system was prepared by workers at the Oak Ridge Gaseous Diffusion Plant (ORGDP) who developed the system. $3,4,5$

The gas leaving the absorption system is cooled regeneratively to $\sim 25 \mathrm{~K}$ and passed through activated carbon adsorption beds for tritium removal. The purified helium then returns through the regenerative heat exchangers for reuse in the pump purge and elsewhere in the system. 


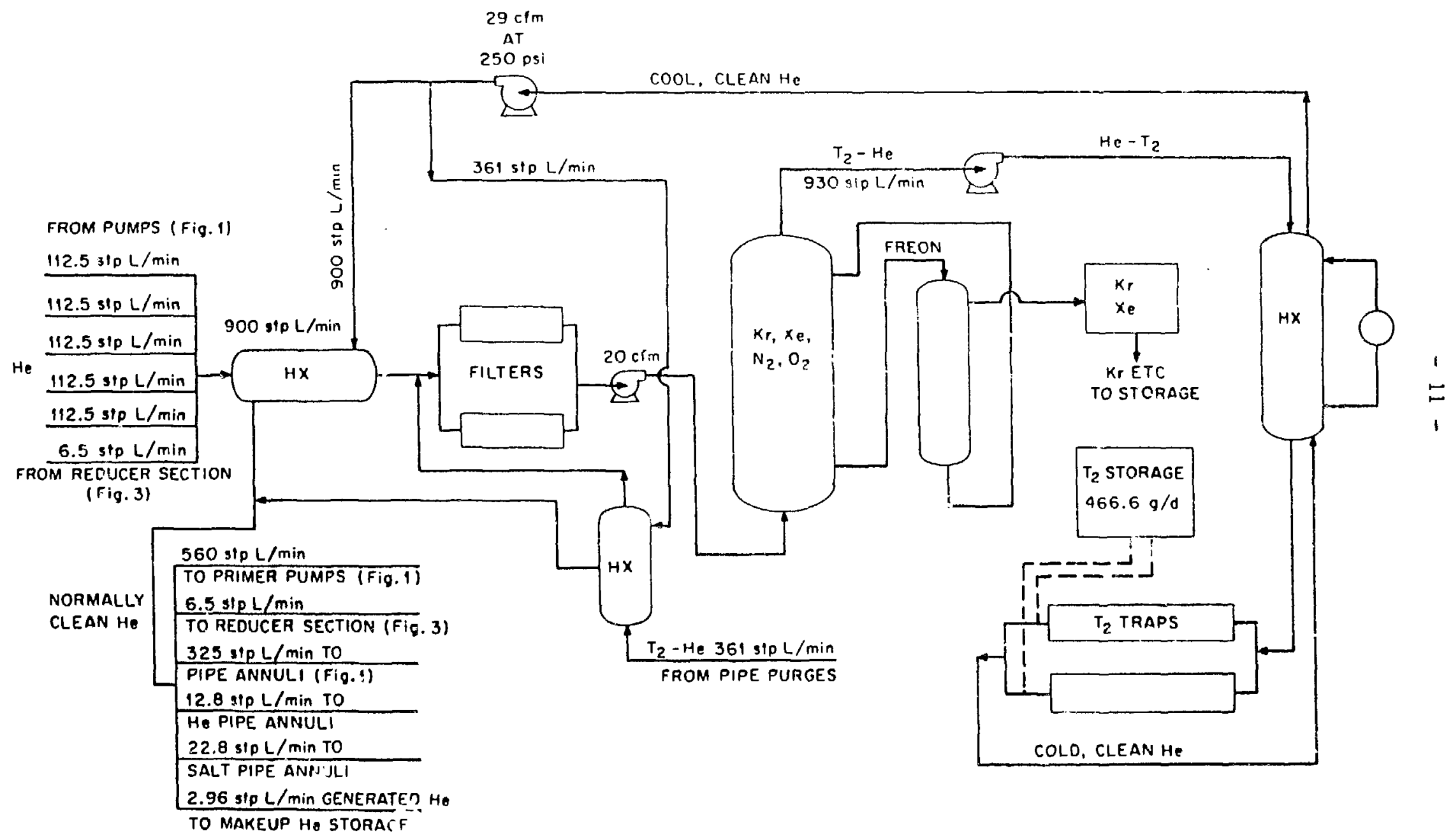


Sa.t.t Reduction (Lithium Addition)

The smaller side streams $(66.67 \mathrm{~L} / \mathrm{min}$ from each salt pump) are combined and sent to a reduction system (shown in Fig. 4). Lithium metal is added to the salt mixture to replace the lithium transmuted to helium and iritium by neutron bombardment in the blanket. The salt is first stripped of any remaining tritium by using a helium purge gas in a metalwesh-parked column $\sim 5.2 \mathrm{~m}$ high and $61 \mathrm{~cm}$ in diameter. The $6.5 \mathrm{~L} /$ min flow of helium stripping gas is then sent through the tritium recovery sysiem for tritium removal. The lithium metal is added to a $1.7 \mathrm{~m}^{3}$ tank of the recirculating salt. Fresh make-up salt is also added at this point to replace the bleed salt necessary to restore the ${ }^{6} \mathrm{Li}$ to ${ }^{7} \mathrm{Li}$ racio. When natural lithium is used in the fresh salt, $60 \mathrm{~L} / \mathrm{d}$ must be added. The sali is then filtered before it is returned to the blanket to remove any undissolved lithium or other precipitated solids.

\section{Uranium Removal}

Only a relatively small salt stream needs to be processed for uranium removal. The principal process step is fluorination of the uranium to volatile UF 6 (see process flowsheet in Fig. 5). The fluorination system is modeled after systems studied and designed for the MSBR. Although a continuous fluorinator ${ }^{6}$ was designed for a conceptual molten salt reactor, a batch fluorinator was used in this study, because only batch fluorinators were tested in larger sizes. 7 The fluorinator residence time chosen for this study was $2 \mathrm{~h}$, which is somewhat shorter than the times used in any experimental batch fluorinations but considerably longer than the residence 


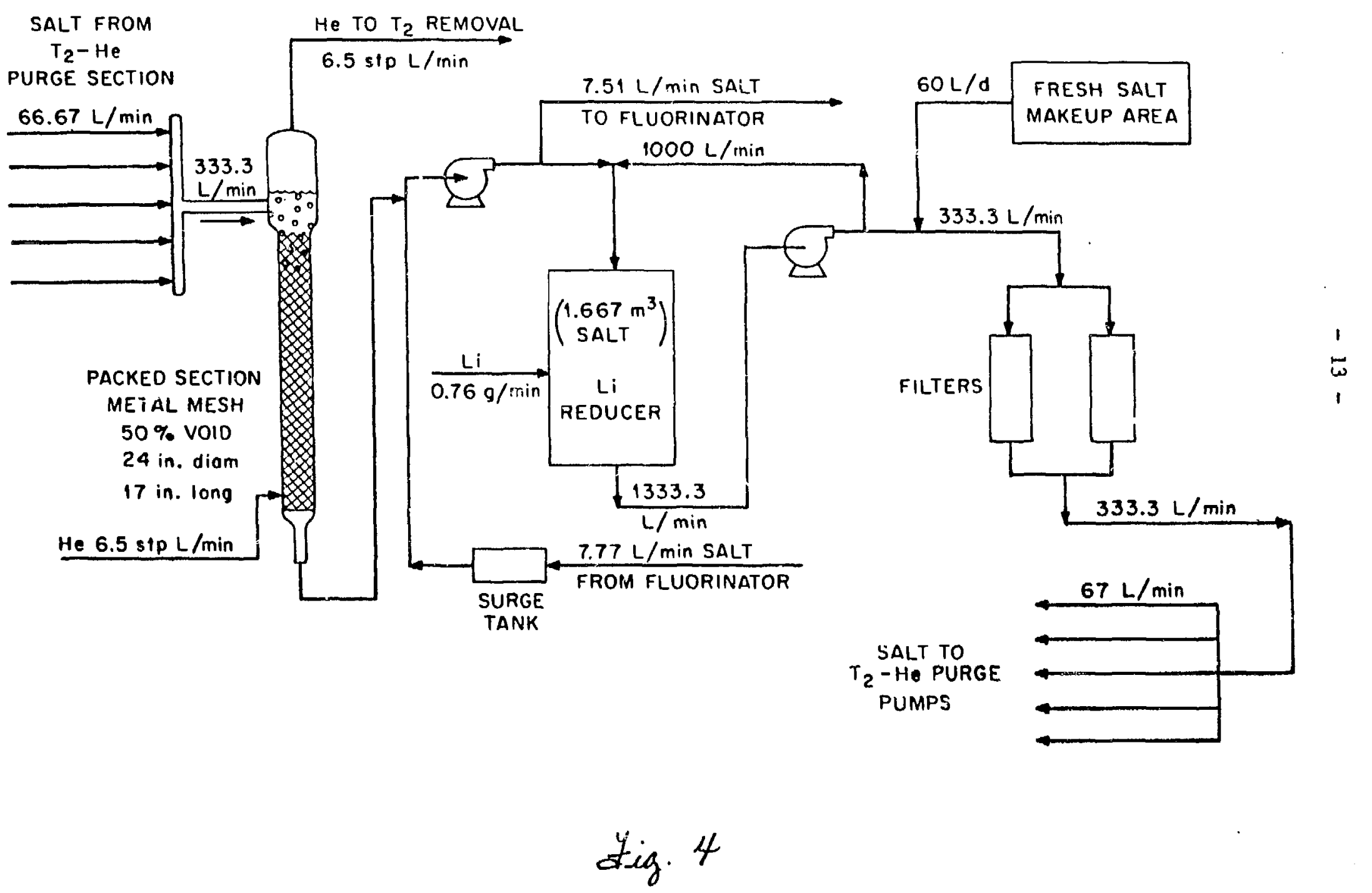




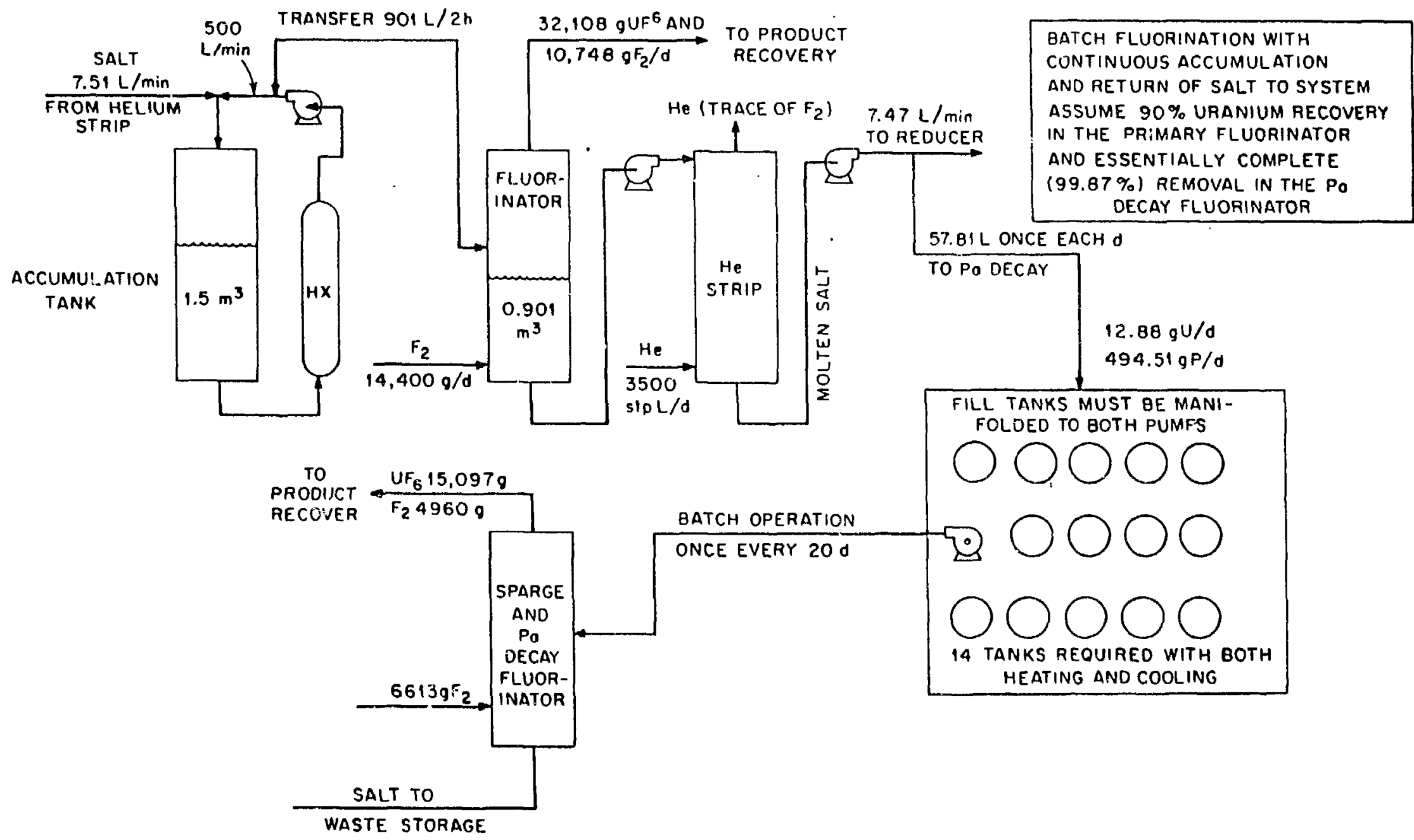

BATCH FLUORINATION WITH CONTINUOUS ACCUMULATION DOVERY RINATOR ANO ESSENTIALLY COMPLETE (99.87\%) REMOVAL IN THE Po DECAY FLUORINATOR

57.81 L ONCE EACH O

TO PO DECAY

$12.88 \mathrm{gU} / \mathrm{d}$

$494.51 \mathrm{~g} P / d$

FILL TANKS MUST BE MANIED TO BOTH PUMFS

tia. 5 
time assumed in other MSBR design studies. The allowable resirience time, like many other aspects of the hybrid reactor, should be investigated, but our assumption is believed to be reasonable, based upor the data currently available.

The fluorinator operates with cooled walls so that salt will be frozen on the walls. This protects the walls from the very corrosive oxidized salt. The frozen-salt wall protection is needed only for surfaces which are likely to be contacted by salt; dry fluorine gas can be contained effectively by nickel and nickel alloys. Frozen-salt wall protection was studied but not demonstrated in the MSBR program. 8,9

Since our cost study is for a batch fluorinator and a continuous salt feed, a $1.5-m^{3}$ accumulation tank is required to hold the feed salt coming from the blanket until +'e fluorinator is ready to accept another batch of salt. There will be $\sim 6 \mathrm{MW}$ of heat generated in this salt, and significant cooling will be required. The fluorinated salt is sent in batches to a similar tank from which salt can be pumped continuously for return to the blanket. A helium-flush is used to remove most of the residual Eluorine but to minimize corrosion problems, the salt also goes through the reduction (lithium addition) system before returning to the blanket. The uranium-bearing fluorine gas from the fluorinator is sent to the uranium recovery system.

To maintain the proper ${ }^{6} \mathrm{Li}$ to ${ }^{7} \mathrm{Li}$ ratio, a small salt bleed stream of $57.8 \mathrm{~L} / \mathrm{d}$ is removed for disposal. This is equivalent to replacing the salt inventory $\left(100 \mathrm{~m}^{3}\right)$ approximately every 5 years. Since all of the uranium is not removed from the salt and since there is still significant 
$233^{\mathrm{Pa}}$ which will decay to ${ }^{23} \mathrm{U}$, the salt must be stored for $260 \mathrm{~d}$ to allow essentially all of the ${ }^{233} \mathrm{~Pa}$ to decay, and then fluorinated to remove almost all of the ${ }^{23} \mathrm{U}$ produced from this decay. During this decay period, the salt will likely be cooled and stored in solid form in one of 14 tanks, each with an effective volume of $1.16 \mathrm{~m}^{3}$. One such tank will be filled each $20 \mathrm{~d}$, and one tank will be pumped to the fluorinator each $20 \mathrm{~d}$ for final uranium removal. The fluorination can be a relatively slow process to remove essantially all of the uranium from the salt. The fluorinated salt will then be sent to disposal.

\section{Uranium Recovery}

The system proposed for recovering uranium from the fluorinator off-gas is modeled after that designed for the MSBR (shown in Fig. 6). The $\mathrm{UF}_{6}$ is trapped on $\mathrm{NaF}$ beds. In the particular flowsheet used in this study, the uranium-free fluorine is reacted with hydrogen, purified, and electrolyzed to recover the fluorine. This is a fairly elaborate purification process. It may he practical to recycle most of the fluorine directly, or to purify only a portion of the fluorine by a scheme such as this, to prevent the accumulation of impurities. The uranium is recovered by periodic regeneration of the NaF beds and purified by distillation. Tha product is $\mathrm{UF}_{6}$, which can be converted to any desired product by conventional technology.

\section{COST ESTIMATE}

The estimated costs of the proposed molten salt blanket processing system are summarized in Table 1. The estimate, including the factored 


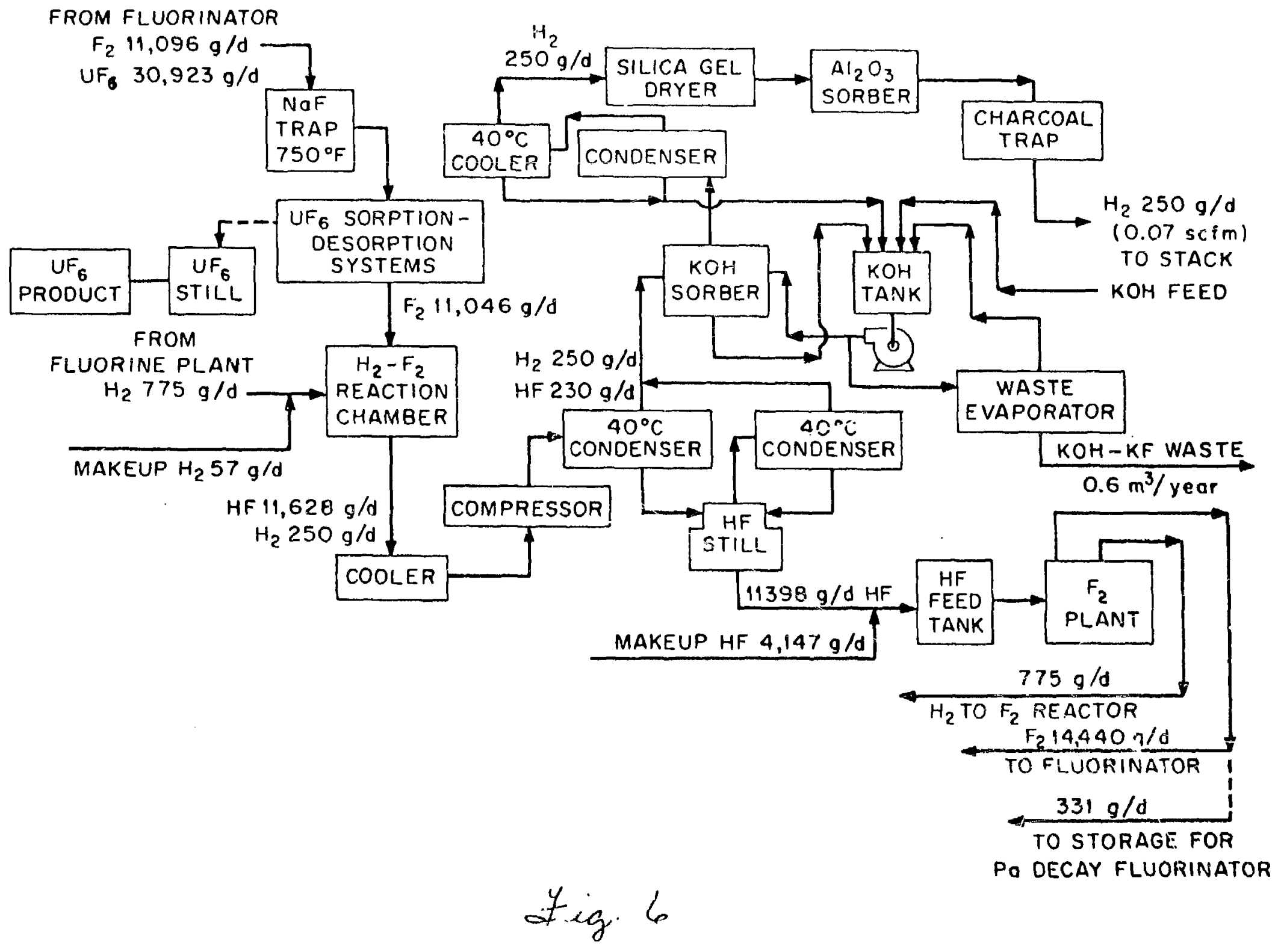


Table 1. Cost estimate summary

Total construction materials

Total construction labor

Engineering costs. (30\%)

Contingency costs ' $50 \%$ )

Total
$\$ 13,822,000$

$18,541,000$

$9,709,000$

$21,036,000$

$\$ 63,108,000$ 
engineering and contingency costs, follows standard procedures used throughout Martin Marietta Energy Systems, Inc. but, in this case, the costs are based upon a conceptuaj. design with numerous uncertainties. Specific estimates were obtained for the major items of equipment, and the cost of associated items and construction labor were assumed to be proportional to the cost of these major items. The estimate is believed to be as reliable as possible at this time and with the available data. As mentioned previously, there are uncertainties in the feasibility as well as in the size and cost estimates for some items in the proposed flowsheet. However, there are no known fundamental reasons why this or a similar system would not work. The degree of uncertainty in this flowsheet and cost estimate is probably no worse than that for several other portions of the fusion/fission hybrid reactor system.

The cost estimates do not include housing for the process equipment, containment, shielding, remote maintenance, or standard utilities. These facilities are assumed to be similar for alternate blanket systems. However, since the relatively high-temperature molten salt system will require additional electrical power, $\$ 750,000$ was included for this purpose. A packaged oil burner for process steam and a 50-MW cooling tower were also included; these added $\$ 2,500,000$ to the material costs and $\$ 1,500,000$ to the labor costs. The process equipment installation is assumed to be at the reactor facility, and the surrounding building is expected to be similar to that required for other process options. Although the molten salt process requires considerable facility space 
for handing equipment and storage of waste salt during protactinium decay, the space is expected to be no more, and may be significantly less, than that required for the most likely alternative, aqueous processing of metal or metal-clad fuels.

The relatively large contingency factor seen in Table 1 is appropriate for conceptual designs such as this, where many details and even some process steps are still uncertain. The estimates for heat exchangers and radioactive off-gas treatment systems are notable items among the process costs; however, neither the costs for these nor those for the entire system are unusually or unacceptably high. The projected costs are believed to be reasonable for a radioactive processing system of this size. The estimates are alco expected to be competitive with those for most, if not all, alternative hybrid reactor processing systems.

\section{ACKNOWLEDGMENTS}

This research was sponsored by the Office of Fusion Energy, U.S. Department of Energy under contract DE-AC05-840R21400 with Martin Marietta Energy Systems, Inc.

\section{REFERENCES}

1. J. D. Lee et al., "Feasibility Study of a Fission-Suppressed TandemMirror Hybrid Reactor," UCID-19327 (1982).

2. R. W. Moir et al., "Helium Cooled Molten Salt Fusion Reactor," (to be published).

3. D. K. Little et al., "Noble Gas Removal and Concentration by Combining Fluorocarbon Absorption and Adsorption Technologies," K/PS-5002 (1982). 
4. R. S. Eby et al., "Single Column Based Absorption Process for Treating Dissolver Off-Gas," K/PS-5005 (1982).

5. R. C. Waggoner, "Technical and Economic Evaluation of Processes for $85 \mathrm{Kr}$ Recovery from Power Fuel Reprocessing Plant off-Gas," DP-1637 (1982).

6. W. L. Carter and E. L. Nicholson, "Design and Cost Study of a Fluorinator--Reductive Extraction--Metal Transfer Processing Plant for the MSBR," ORNL/TM-3579 (1972).

7. R. B. Lindauer, "Processing of the MSRE Flush and Fuel Salts," ORNL/TM-2578 (1969).

8. R. M. Counce and J. R. Hightower, Jr., "Engineering Development Stucies for Molten-Salt Breeder Reactor Processing. No. 18," ORNL/TM-4698(1975).

9. L. E. McNeese, "Molten-Salt Reactor Program: Semiannual Progress Report for Period Ending February 28, 1975," ORNL-5047 (1975). 
FIGURE CAPTIONS

DWG. NO.

Fig. 1. Schematic cross section of hybrid molten salt reactor blanket module.

$85-295$

$85-292$

$85-293$

$85-291$

$85-290$
Fig. 2. Molten salt manifold system.

Fig. 3. Tritium recovery system.

Fig. 4. Salt reduction system.

Fig. 5. Fluorination system.

Fig. 6. Uranium recovery system. 